SUST, 2021, 1(2): 000007

Sustainable Structures

ISSN: 2789-3111 (Print); ISSN: 2789-312X (Online)

http://www.sustain-dpl.com/picnews.asp?id=155

DOI: $10.54113 /$ j.sust.2021.000007

ORIGINAL ARTICLE

\title{
Experimental estimation of energy dissipated by multistorey post-tensioned timber framed buildings with anti-seismic dissipative devices
}

\author{
Felice Carlo Ponzo $^{a}$, Di Cesare Antonio ${ }^{\text {a }}$, Lamarucciola Nicla ${ }^{\text {a, }}$, Domenico Nigro ${ }^{\text {a }}$ \\ aSchool of Engineering, University of Basilicata, Viale dell'Ateneo Lucano n.10, Potenza 85100, Italy. \\ ${ }^{*}$ Corresponding Author: Nicla Lamarucciola. Email: nicla.lamarucciola@unibas.it.
}

\begin{abstract}
The need to satisfy high seismic performance of structures and to comply with the latest worldwide policies of environmental sustainability is leading engineers and researchers to higher interest in timber buildings. A posttensioned timber frame specimen was tested at the structural laboratory of the University of Basilicata in Italy, in three different configurations: i) without dissipation (post-tensioning only-F configuration); ii) with dissipative angles (DFdissipative rocking configuration) and iii) with dissipative bracing systems (BF braced frame configuration). The shaking table tests were performed considering a set of spectra-compatible seismic inputs at different seismic intensities. This paper describes the experimental estimation of energy dissipated by multistorey post-tensioned timber prototype frame with different anti-seismic hysteretic dissipative devices used in the DF and BF testing configurations. The main experimental seismic key parameters have also been investigated in all testing configurations.
\end{abstract}

Keywords: Shaking table tests; post-tensioned timber framed buildings; energy dissipated; dissipative bracing systems; hysteretic devices

\section{Introduction}

In recent years, Europe Union strategies and worldwide policies are moving towards the reduction of greenhouse gas emissions and there is an increased trend to consider again timber as construction material for multi-storey buildings optimizing the structural concept and the seismic design, with the dual purpose to obtain more sustainable and anti-seismic constructions. In order to significantly reduce structural and non-structural damage and avoid high economic loss due to strong seismic events, in the last decades research studies focused on the development of low damage design and technologies [1-5].

The application of the displacement based design (DBD) procedure has been extended toward the design of timber buildings and in order to improve the seismic performance a recent technology of posttensioned timber frame has been developed. This technique is based on the PREcast Seismic Structural System (PRESSS), originally developed at University of California (San Diego) by Priestley et al. [6] for precast concrete frame and wall constructions. The system, successfully applied to create timber jointed ductile connections at the University of Canterbury (New Zealand) [7], consists in the use of high strength unbounded steel cables or bars to connect timber beams and columns, or columns and walls to their

000007-1

Received: 28 August 2021; Received in revised form: 21 October 2021; Accepted: 28 November 2021 This work is licensed under a Creative Commons Attribution 4.0 International License. 
foundations, providing self-centering capability to the frame. In order to increase the seismic performance internal or external dampers are added, to provide additional strength and energy dissipation capability. This low damage system allows to significantly reduce the damage to the structural and non-structural members by dissipating earthquake energy using energy dissipation dampers, in which the eventual damage is concentrated. The choice of metallic yielding dampers represented an optimal low-cost solution requiring a little maintenance and easily replaceable in case of damage.

The hysteretic energy dissipation absorbed by a structural system during an earthquake excitation is a useful seismic performance key factor, besides maximum displacement and interstorey drift, which can be also related to the amount of damage in it [8-9], demonstrating that the energy-dissipation capability varied significantly after the structure experiences seismic damage [5]. Moreover, there is a good correlation between the hysteretic energy dissipated and inelastic deformation/acceleration demands of a structure composed by structural members with stable hysteretic loops and large hysteretic energy dissipation capacity, representing a better system performance. The concept of energy absorbed by hysteretic cyclic response of a system was introduced by Jacobsen (1960) [10] through equivalent linearization techniques in analytical studies and it was associated to the area of hysteretic loops in experimental tests and used in several studies [11]. This concept was used to estimate the damping of numerous composite structures and also applied for timber structures [12-13].

In this paper the experimental estimation of energy dissipated by a post-tensioned timber frame building tested with different anti-seismic hysteretic devices has been presented, based on the area under the base shear-displacement curve performed during experimental tests. A multistorey post-tensioned timber frame specimen was tested at the structural Laboratory of University pf Basilicata, alternatively combining the bare frame with two different types of energy dissipation systems [14-15]. The seismic response in terms of the main global and local hysteretic behaviour has been discussed and the amount of hysteretic energy dissipated by the different damper devices and by the frame have been investigated considering different seismic inputs at increasing PGA level, from a Service Level Earthquake (SLE) to a Design Base Earthquake (DBE).

\section{Experimental model}

The experimental model was a 3-D, 3-storey, 2/3 scaled post-tensioned glulam timber frame characterized by single bays in both directions, with dimensions in plant of $4 \mathrm{~m} \mathrm{x} 3 \mathrm{~m}$ and inter-storey height of $2 \mathrm{~m}$ [14-15]. The prototype model was designed according to European code [16] for office use at first and second floors (live load of $\mathrm{Q}=3 \mathrm{kPa}$ ) and considering a rooftop garden load $(\mathrm{Q}=2 \mathrm{kPa})$. The testing frame was realized using glulam grade GL32h [17] and it was post-tensioned at the beam-column joints in both directions. Suitable scale factors were applied to the prototype model based on the CauchyFroude similitude laws [18]. The frame was designed and tested at the structural laboratory of the University of Basilicata in three different configurations: i ) F configuration (Fig. 1a), with post-tensioning only; ii) DF configuration with dissipative steel angles at the beam column and column foundation joints [19] and iii) BF configuration (Fig. 1b) with dissipative bracing systems [20] composed by V-inverted timber roads and two U-shaped flexural plate (UFP) steel dampers. Fig. 1c and Fig 1d show the construction detail of the beam column joint in DF configuration and of the dissipative bracing connection with UFPs in BF configuration, respectively. Table 1 summarizes the loads of the prototype frame in DF and BF configurations.

The experimental campaign was performed using a set of seven natural earthquake records, selected from the European strong motion database. These spectra-compatible records were defined according to the current Eurocode [16] considering a peak ground acceleration PGA of $0.44 \mathrm{~g}$ and medium soil class (type B) in high seismic zone, and they were opportunely reduced by means of appropriate scale factors. A reduced set of three selected seismic inputs has been considered in this paper as shown in Fig. 2. During shake table testing the frame was tested considering all seismic inputs at different intensities, from $10 \%$ to $100 \%$ of PGA level. 
The seismic response of the frame was recorded by more than 50 acquisition channels in all configurations. Different types of sensors were installed on the test frame, providing measurements of acceleration, displacement force and strain. More details about the sections size, the connection details and the instrumentation can be found in Di Cesare et al. [15].

Table 1. Loads of the DF and BF prototype frames.

\begin{tabular}{cccccc}
\hline Level & $\begin{array}{c}\text { DF model } \\
(\mathrm{kN})\end{array}$ & $\begin{array}{c}\text { BF model } \\
(\mathrm{kN})\end{array}$ & $\begin{array}{c}\text { Additional } \\
\text { masses }(\mathrm{kN})\end{array}$ & $\begin{array}{c}\text { Total weight DF } \\
(\mathrm{kN})\end{array}$ & $\begin{array}{c}\text { Total weight BF } \\
(\mathrm{kN})\end{array}$ \\
\hline 1 and 2 & 10.7 & 11.2 & 44.1 & 54.8 & 55.8 \\
3 & 9.9 & 10.4 & 44.1 & 54.0 & 54.5 \\
\hline
\end{tabular}

a)

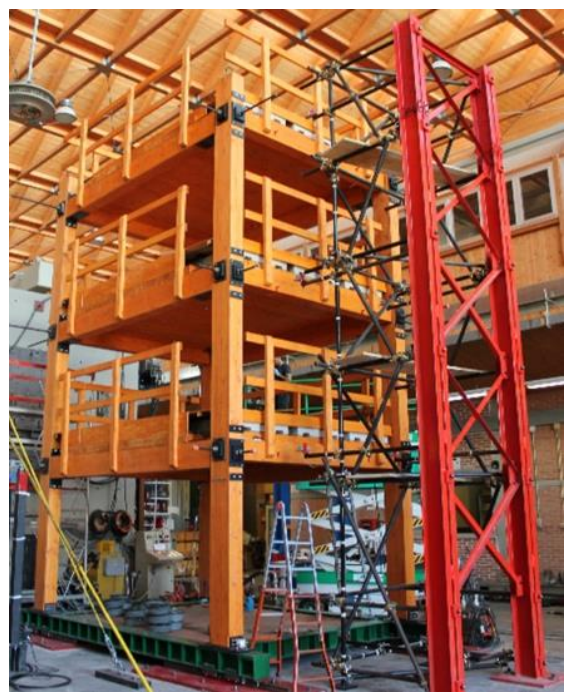

c)

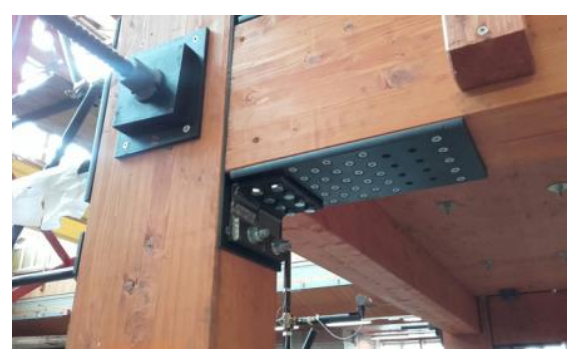

b)

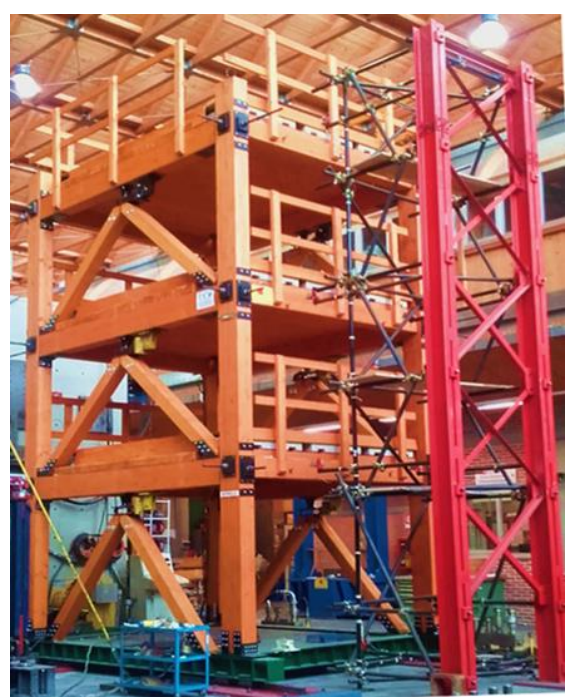

d)

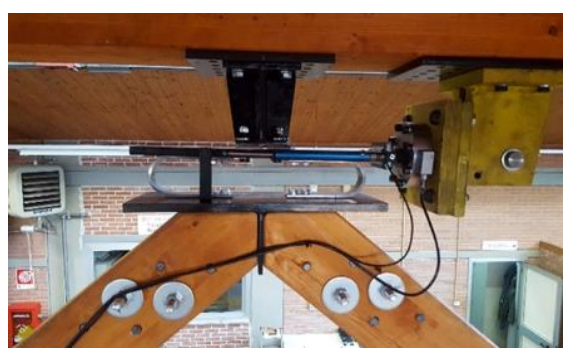

Fig. 1. General views of experimental model at the structural laboratory of University of Basilicata: a) posttensioned timber bare frame (F configuration) (extracted from Di Cesare A et al. [15] paper); b) post-tensioned model with dissipative bracing systems (BF configuration); c) detail of the beam column connection (DF configuration); d) detail of the dissipative bracing system (extracted from Di Cesare A et al. [22] paper).

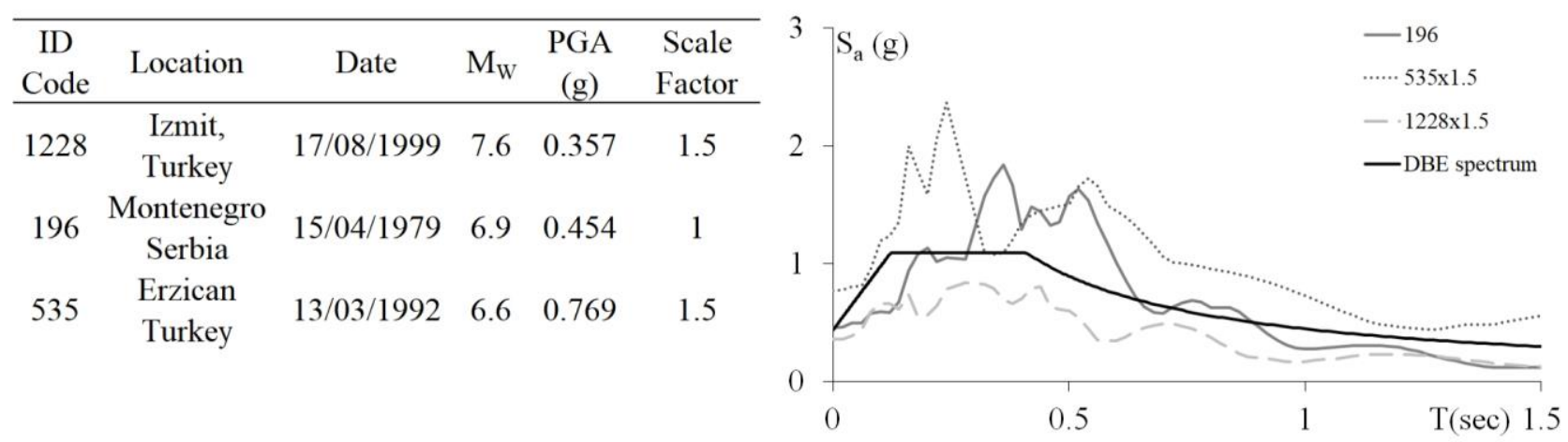

Fig. 2. Main characteristics of the three selected earthquakes. 


\section{Experimental results}

\subsection{Global seismic response}

Fig. 3 shows the global seismic hysteretic response in terms of base shear vs inter-storey drift for F, DF and BF testing configurations for the three selected seismic inputs at $75 \%$ of PGA level. The global flag shape hysteretic loop was more evident for strongest earthquake inputs 196 and 535, with the capability to absorb energy while rocking back to the undamaged position after the shaking. In case of tests with earthquake EQ535, it is evident that the seismic response of the structure was drastically reduced in terms of drift amplitude with a slight increase in base shear when the dissipative bracing systems were introduced.

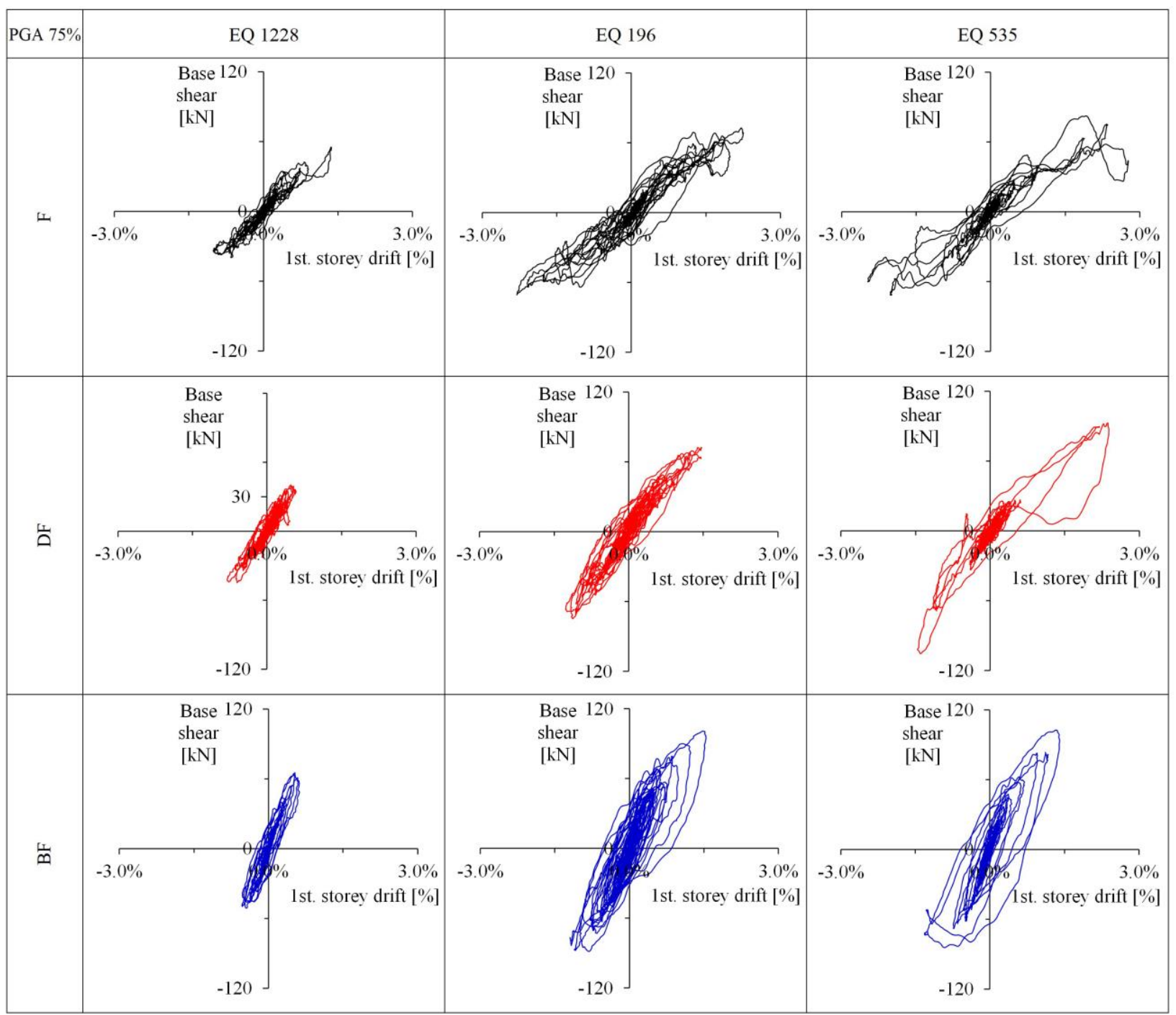

Fig.3. Base shear vs inter-storey drift for selected seismic inputs of all testing configurations at $75 \%$ of PGA.

Fig. 4 shows the mean values of maximum $1^{\text {st }}$ storey drift and base shear for the three configurations at all PGA levels. As can be observed both drift and base shear increase linearly with the increase of the ground motion intensity. At lower seismic intensities (up to 25\% - SLE) no significant variations of drift between the three testing configurations were observed, because the hysteretic devices remained substantially elastic. At higher PGA levels the dissipative bracing systems of BF model a significant reduction of storey drift was observed, with a slightly increase of base shear, due to the stiffness of the bracing system [15]. In particular at 100\% of PGA the drift reduced of about $30 \%$ than the DF configuration. 


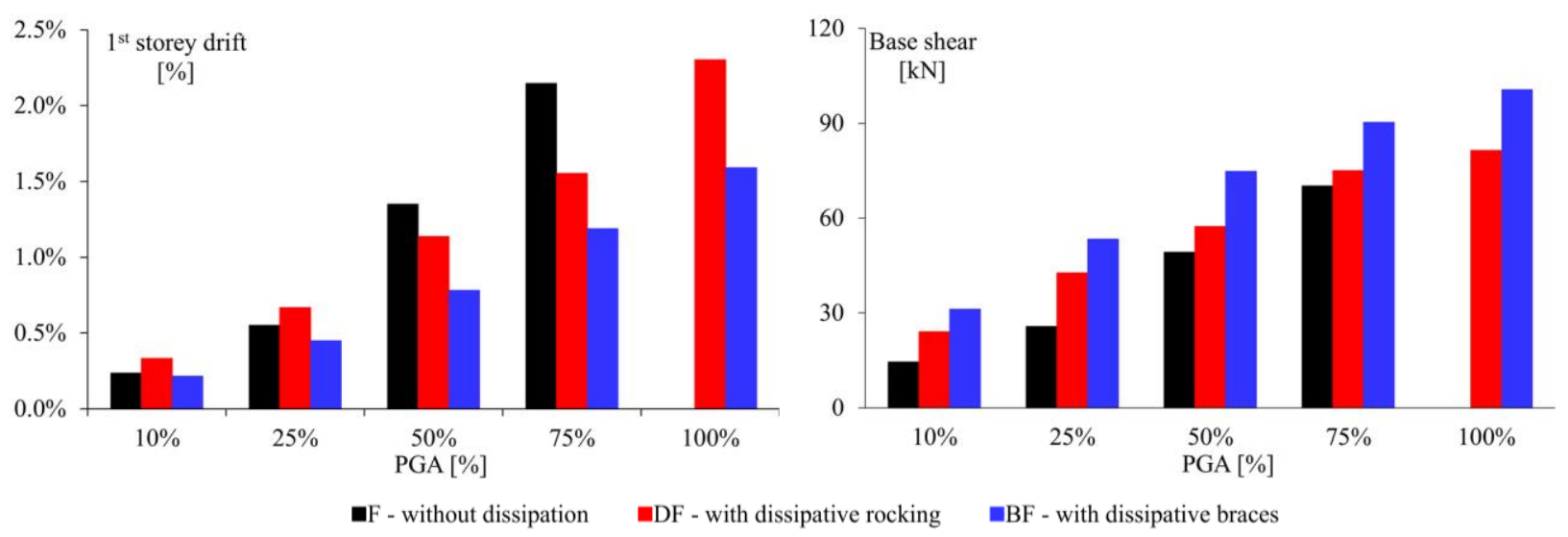

Fig. 4. Mean of maximum values evaluated for 1228, 196 and 535 seismic inputs in terms of base shear and 1st storey drift for the F, DF and BF testing configurations at all PGA levels.

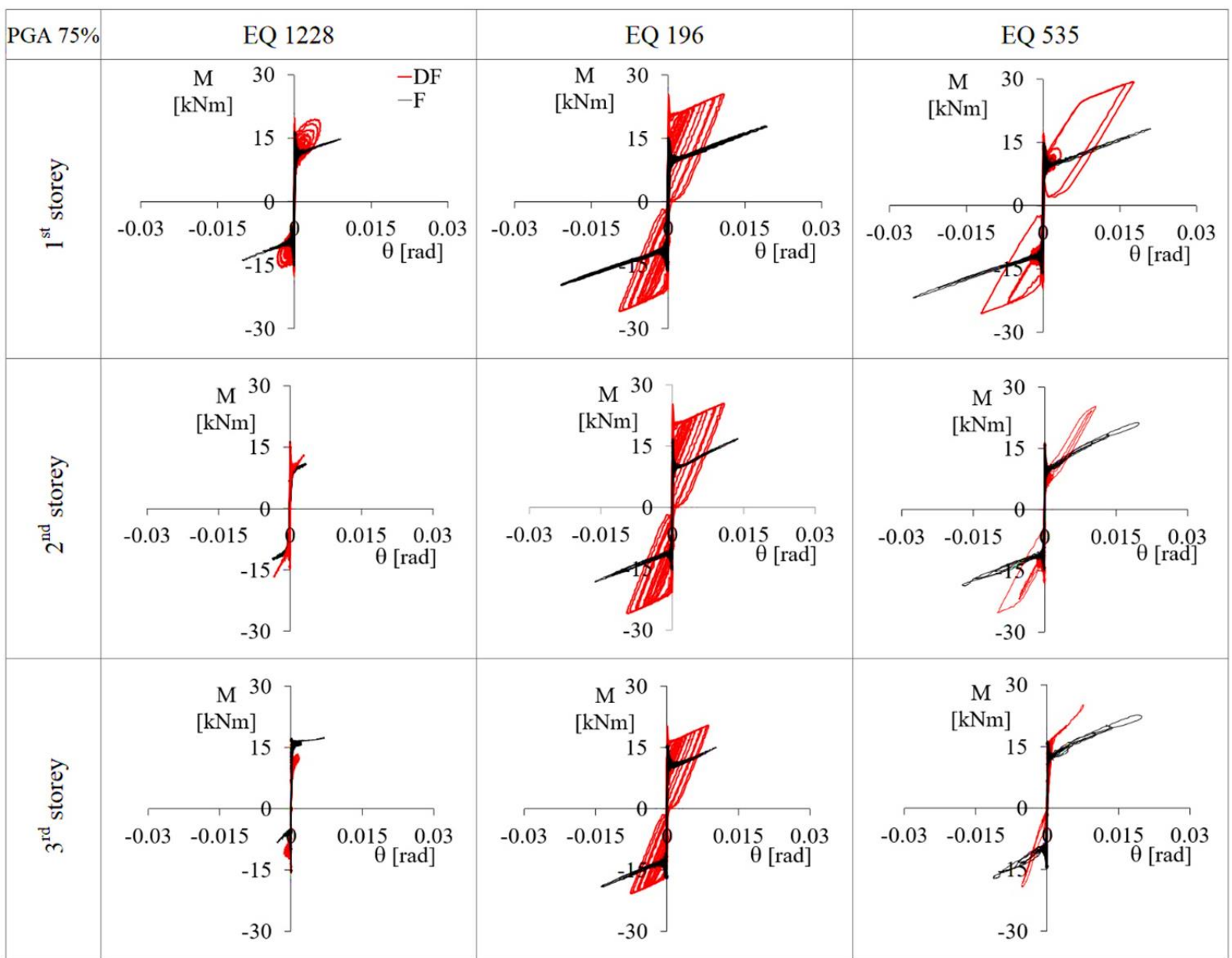

Fig. 5. Moment- rotation of the beam-column connection at the three storey in $\mathrm{F}$ and $\mathrm{DF}$ configurations for seismic inputs 1228,196 and 535 at $75 \%$ of PGA level.

\subsection{Local seismic response}

Fig. 5 shows the local response of the beam-column joint in terms of moment - rotation of the connection without and with dissipative steel angles ( $F$ and DF configurations, respectively) at the three 
stories of the prototype frame for 1228, 196 and 535 seismic inputs at 75\% of PGA level. The complete self-centering capability of $\mathrm{F}$ configuration and the dissipative capacity with the typical flag-shaped behaviour of DF configuration of the post-tensioned beam-column joints at the three stories were clearly observed for all seismic inputs.

Fig. 6 shows the local hysteresis of the UFP dampers at the three storey of the braced frame BF in terms of force-displacement for the selected ground motions at $75 \%$ of PGA level. The UFPs were activated at all the three stories (UFP1, UFP2 and UFP3) showed a stable hysteretic behaviour without degradation in strength and stiffness and without failure for a high number of consecutive cycles.

For more details about other important global key parameters (e.g. acceleration, post-tensioning, equivalent damping) and local key parameters of the devices (e.g. number of cycles of UFPs) please refer to [13-15], [21-22].

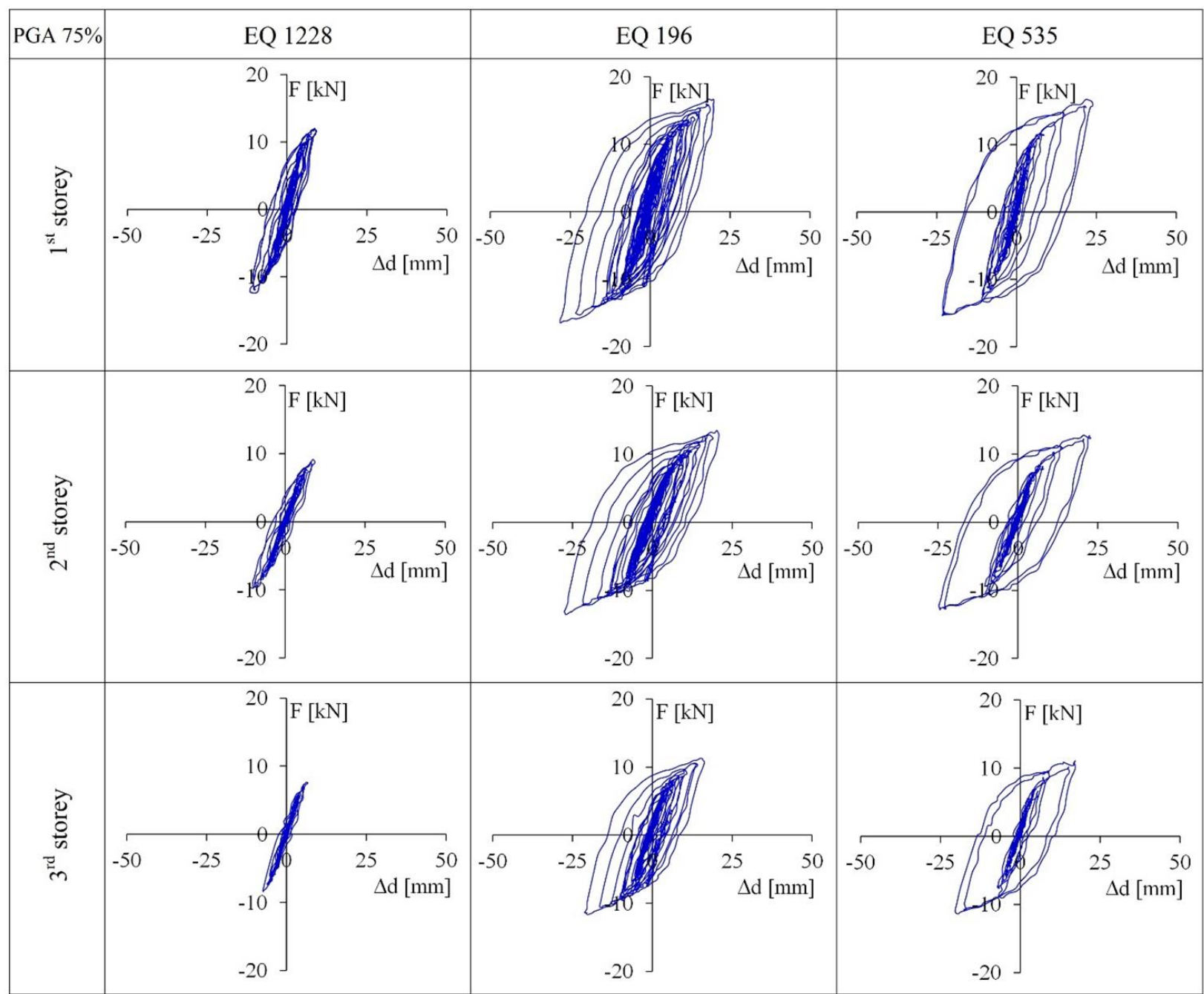

Fig. 6. Force-displacement of UFPs of each storey of the BF model for selected seismic inputs at $75 \%$ of PGA

\subsection{Energy dissipation}

The overall hysteretic energy dissipation of the timber frame is a reflection of many contributors, mainly including the yielding of hysteretic steel dampers (steel angles and UFPs) and nonlinear geometric behaviour of rocking mechanisms of beam-column joints and of column-foundation connections. The hysteretic response of the timber structure is mainly governed by the dissipative connections of the 
structural members during the seismic motions and is also a function of the seismic input energy.

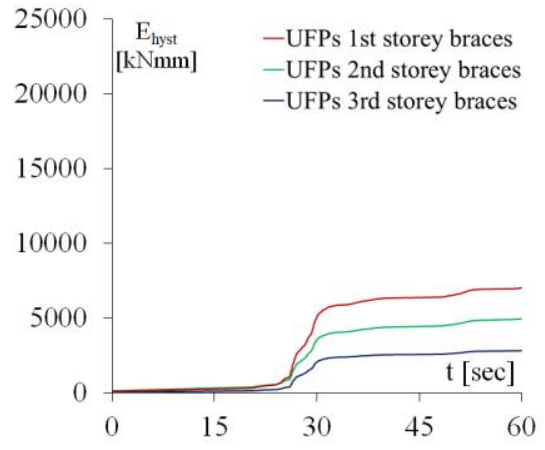

(a) $1228100 \%$

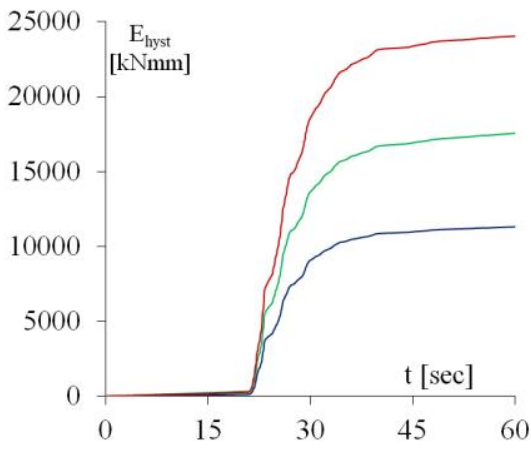

(b) $196100 \%$

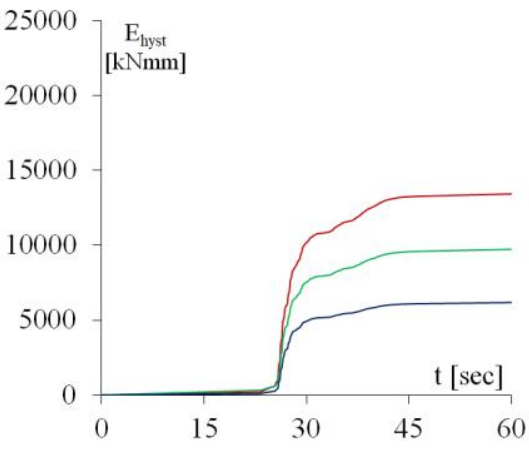

(c) $535100 \%$

Fig. 7. Comparison between cumulated hysteretic energy dissipated by UFP devices installed into dissipative braces at the three storey of the post-tensioned timber BF model for the selected seismic inputs at $100 \%$ of PGA.

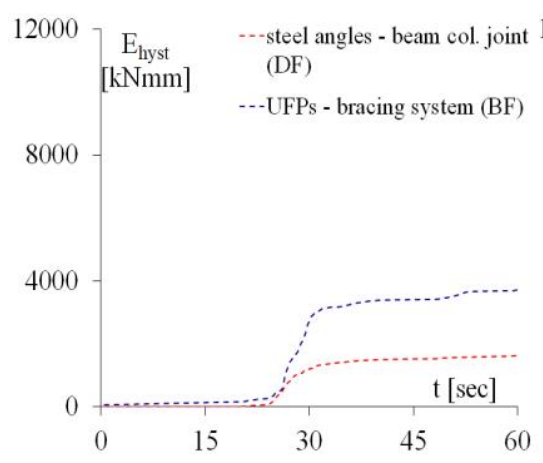

(a) $1228100 \%$

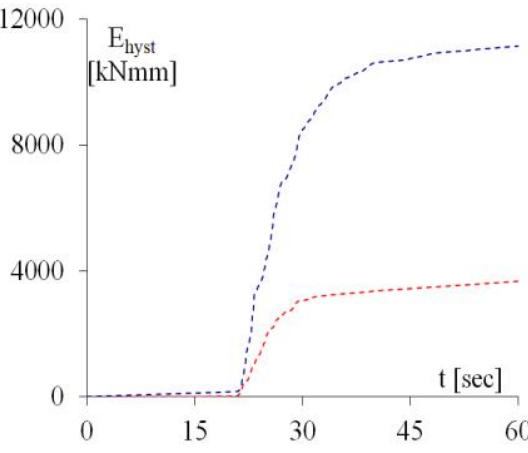

(b) $196100 \%$

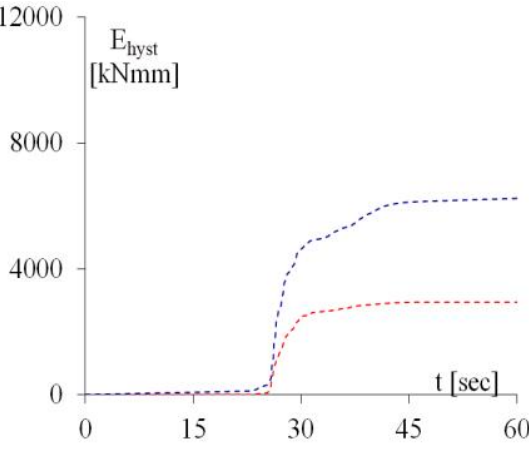

(c) $535100 \%$

Fig. 8. Comparison between cumulated hysteretic energy of the couple UFP devices installed into the single dissipative brace at the first storey of the BF model configuration and the couple of dissipative angles installed at the single beam column connection at the first storey of the DF model configuration for the selected seismic inputs at $100 \%$ of PGA.

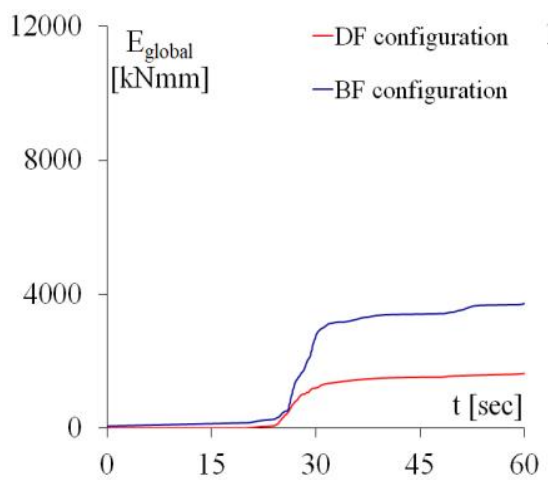

(a) $1228100 \%$

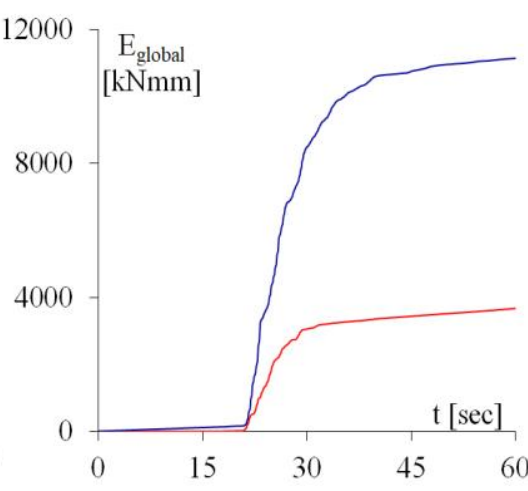

(b) $196100 \%$

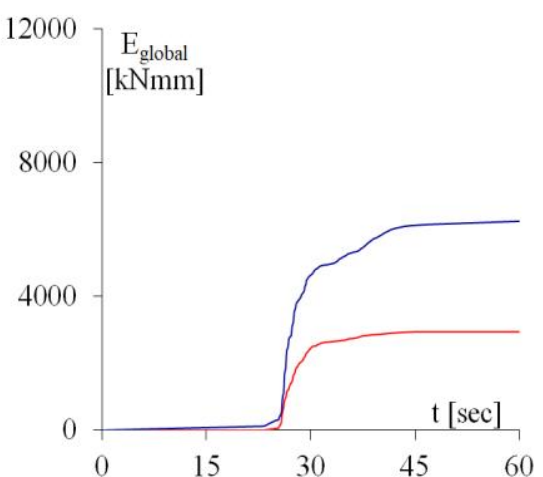

(c) $535100 \%$

Fig. 9. Comparison between global energy dissipated by the DF and BF models for 1228, 196 and 535 earthquakes at $100 \%$ of PGA level.

Fig. 7 shows the estimation of the cumulated hysteretic energy dissipated by the two couple of UFP devices installed at each storey of the BF model into dissipative braces (two UFPs for each side) for the 1228, 196 and 535 seismic inputs at 100\% of PGA level. As can be observed, different amounts of hysteretic 
energy have been dissipated by UFPs, that reduced by passing from $1^{\text {st }}$ to $3^{\text {rd }}$ storey, which can be related to the different geometrical characteristics (reduced widths) of the devices.

Fig. 8 shows the comparison between cumulated hysteretic energy dissipated by the dampers (two UFPs) installed into the $\mathrm{V}$-inverted bracing at the $1^{\text {st }}$ storey of the BF model configuration and the dissipative angles installed at each beam column connection (two ID5A [14]) at the $1^{\text {st }}$ storey of the DF model configuration for the three selected seismic inputs at 100\% of PGA. The amount of hysteretic energy dissipated by the steel angles and UFPs has been estimated based on the area of the hysteretic loops of the local force-displacement response. As can be observed the hysteretic energy dissipation capacity significantly increase when UFP dampers are introduced into the model, as expected by design. This can be related to the capacity of the UFP flexural devices to sustain higher cumulative displacements compared to the steel angle devices. The different amounts of energy dissipated between the three seismic motions is related to the different characteristics of the earthquakes, with different input energy.

Fig. 9 shows the global energy dissipated, estimated based on the area of the hysteretic loops of the the global hysteretic curves of DF and BF models, for 1228, 196 and 535 seismic inputs at 100\% of PGA level. As can be observed, the global amount of dissipated energy reflects the response of the local hysteretic energy dissipated by steel angles and UFPs, with higher amount of energy dissipated by the BF model. It can be observed a higher amount of energy dissipated for the strongest seismic inputs 196 and 535 .

Fig. 10a shows maximum values of the global energy dissipated for DF and BF configurations for the three selected seismic inputs at all PGA level and the corresponding mean value. The maximum energy dissipated tends to increase linearly with the increase of the intensity of ground motions, in particular from $50 \%$ to $100 \%$ of PGA. It can be observed that up to SLE $(<25 \%$ of PGA level) the maximum energy dissipated is almost similar between DF and BF model configurations because the dampers are not yet activated, while at higher PGA levels ( $>50 \%$ of PGA) the effect of dissipative bracing (BF model) is evident with higher amount of energy dissipated respect to DF model. Fig. 10b shows the maximum drift versus the dissipated energy of the timber frame in DF and BF configurations. A linear trend can be observed for both configurations. It can be pointed out that at the same level of energy dissipated a reduced inter-storey drift has been observed for the BF model, demonstrating the higher energy dissipation capability of the dissipative bracing systems introduced, as expected by design.

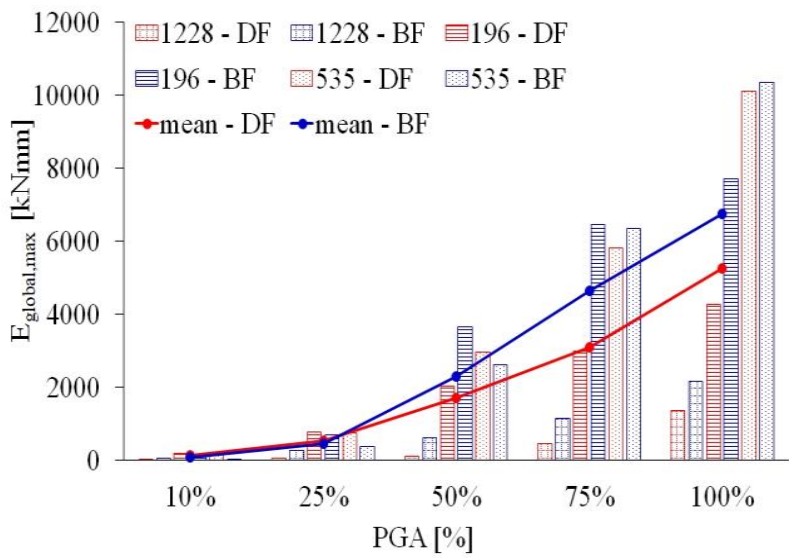

(a)

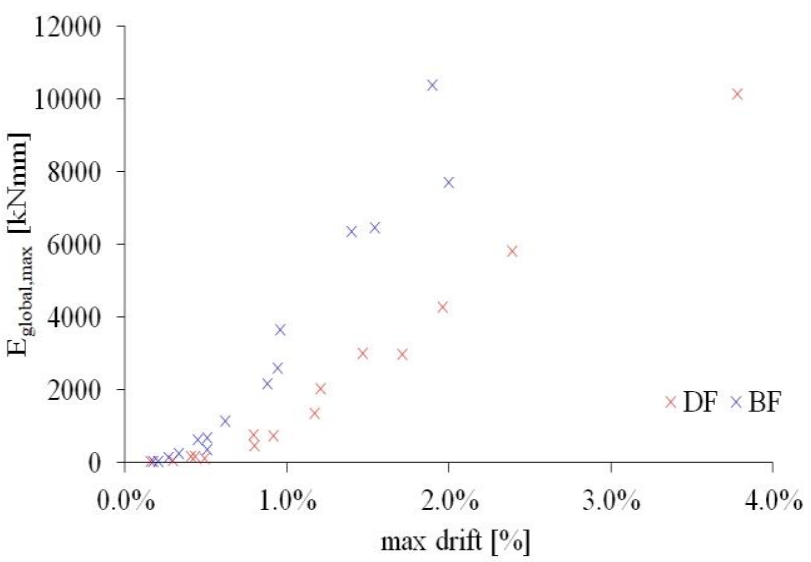

(b)

Fig. 10. (a) Maximum global energy dissipated by DF and BF models for the three selected seismic inputs at all PGA levels and corresponding mean value; (b) Maximum global energy dissipated versus maximum displacement for all seismic tests in DF and BF configurations.

\section{Conclusions}

In this study the experimental energy dissipated by post-tensioned timber frame structures with different anti-seismic devices has been investigated. A 3D, 3 storey post-tensioned timber frame prototype 
building has been dynamically tested at the structural laboratory of the University of Basilicata in three different configurations: with post tensioning only $(\mathrm{F})$, with dissipative steel angles at the joint connections (DF) and with dissipative bracing systems (BF).

The global and local hysteretic response of the frame in terms of fundamental seismic key indicators and of hysteretic energy dissipated by the steel dampers and by the timber frame in DF and BF configurations have been evaluated. The global hysteretic response of the post-tensioned timber frame with dissipative systems showed a flag-shaped behaviour with a complete re-centering capability. The BF model showed a significant reduction of the storey drift respect to the F and DF configuration, with a slightly increase of base shear. The local response of both steel angles and UFP devices showed a stable hysteretic behaviour at all stories. The estimation of the cumulated hysteretic energy dissipated by UFP devices of the bracing system showed an increase of more than two times respect to the steel angles at the beam column joints, demonstrating the excellent dissipative capacity of the system. The global energy dissipated by the BF model was higher more than $25 \%$ respect to the DF model at highest intensity levels (from $50 \%$ to $100 \%$ of PGA).

All experimental results demonstrated the robustness of the design procedure and show that the introduction of dissipative bracing systems allowed an improvement of the seismic response of the posttensioned timber frame.

\section{Funding Statement}

This study was supported by Structural Timber Innovation Company (STIC, New Zealand), FederLegnoArredo (FLA, Italy) and DPC-RELUIS 2019-2021.

\section{Conflicts of Interest}

The authors declare no conflict of interest. The funders had no role in the design of the study; in the collection, analyses, or interpretation of data; in the writing of the manuscript, or in the decision to publish the results.

\section{References}

[1] Gallo PQ, Carradine DM, Bazaez R. State of the art and practice of seismic-resistant hybrid timber structures. European Journal of Wood and Wood Products 2021; 79(1): 5-28. https://doi.org/10.1007/s00107-020-01556-3.

[2] Ugalde D, Almazán J, Santa María H, Guindos P. Seismic protection technologies for timber structures: a review. European Journal of Wood and Wood Products 2019; 77: 173-194. https://doi.org/10.1007/s00107-019-01389-9.

[3] Di Cesare A, Ponzo FC, Nigro D. Assessment of the performance of hysteretic energy dissipation bracing systems. Bulletin of Earthquake Engineering 2014; 12(6): 2777-2796. https://doi.org/10.1007/s10518-014-9623-z.

[4] Zhang Y, De Risi R, Alexander N. A frictional sliding on a sprung slope (FSSS) device that axiomatically confers energy dissipation with re-centring to post-tensioned (PT) frames: A conceptual study. Engineering Structures 2021; 244: 112794. https://doi.org/10.1016/j.engstruct.2021.112794.

[5] $\mathrm{Pu} \mathrm{W,} \mathrm{Wu} \mathrm{M.} \mathrm{Energy-based} \mathrm{estimation} \mathrm{of} \mathrm{ductility} \mathrm{demand} \mathrm{of} \mathrm{slip-hysteretic} \mathrm{timber} \mathrm{house} \mathrm{structures} \mathrm{subjected}$ to sequential earthquakes. Structures 2021; 34: 4193-4203. https://doi.org/10.1016/j.istruc.2021.10.025.

[6] Priestley M, Sritharan S, Conley J, Pampanin S. Preliminary Results and Conclusions from the PRESSS FiveStory Precast Concrete Test Building. PCI Journal 1999; 44: 42-67. https://doi.org/10.15554/pcij.11011999.42.67.

[7] Palermo A, Pampanin S, Buchanan A, Newcombe M. Seismic Design of Multi-Storey Buildings using Laminated Veneer Lumber (LVL). NZSEE Conference 2005; Taupo, New Zealand. http://hdl.handle.net/10092/266.

[8] Bojorquez E, Teran-Gilmore A, Ruiz S, Reyes-Salazar A. Evaluation of structural reliability of steel frames: Interstory drift versus plastic hysteretic energy. Earthquake Spectra 2011; 27(3): 661-682. https://doi.org/10.1193 /1.3609856.

[9] Park Y, Ang A, Wen Y. Damage-limiting aseismic design of buildings. Earthquake Spectra 1987; 3(1): 1-26. https: //doi.org/10.1193/1.1585416. 
[10] Jacobsen, L. S. (1960). Damping in composite structures. Proc., 2nd World Conf. on Earthquake Engineering, Science Council of Japan, Tokyo, 2: 1029-1044.

[11] Kazantzi A, Vamvatsikos D. The hysteretic energy as a performance measure in analytical studies. Earthquake Spectra 2018; 34(2): 719-739. https://doi.org/10.1193/112816EQS207M.

[12] Filiatrault A, Isoda H, Folz B. Hysteretic damping of wood framed buildings. Engineering Structures 2003; 25(4): 461-471. https://doi.org/10.1016/S0141-0296(02)00187-6.

[13] Di Cesare A, Ponzo FC, Lamarucciola N, Nigro D. Experimental estimation of equivalent viscous damping for post-tensioned timber framed buildings with dissipative bracing systems, World Conference on Timber Engineering. streamed from Santiago Chile 2021; 9-12 August.

[14] Di Cesare A, Ponzo FC, Nigro D, Pampanin S, Smith T. Shaking table testing of post-tensioned timber frame building with passive energy dissipation systems. Bulletin of Earthquake Engineering 2017; 15(10): 4475-4498. https://doi.org/10.1007/s10518-017-0115-9.

[15] Di Cesare A, Ponzo FC, Lamarucciola N, Nigro D. Experimental seismic response of a resilient 3-storey posttensioned timber framed building with dissipative braces. Bulletin of Earthquake Engineering 2020; 18(15): 6825-6848. https://doi.org/10.1007/s10518-020-00969-y.

[16] UNI EN 1998-1: 2013. EUROCODE 8 - Design of Structures for Earthquake Resistance - Part 1: General Rules, Seismic Actions and Rules for Buildings. European Committee for Standardization. https://doi.org/10.1007/9783-642-41714-6_51763.

[17] Calderoni B, Bedon C, Brunetti M, Ceraldi C, Zanon P. CNR-DT 206 R1/2018 - Istruzioni per la Progettazione, l'Esecuzione ed il Controllo delle Strutture di Legno. 2018. http://hdl.handle.net/11368/2934896.

[18] Krawinkler H, Moncarz PD. (1981). Theory and Application of Experimental Model Analysis in Earthquake Engineering. Stanford University 1981; CA: NASA STI/Recon Technical Report N 82.

[19] Di Cesare A, Ponzo FC, Pampanin S, Smith T, Nigro D, Lamarucciola N. Displacement based design of posttensioned timber framed buildings with dissipative rocking mechanism. Soil Dynamics and Earthquake Engineering 2019; 116: 317-330. https://doi.org/10.1016/j.soildyn.2018.10.019.

[20] Di Cesare A, Ponzo FC, Lamarucciola N, Nigro D. Seismic design and testing of post-tensioned timber buildings with dissipative bracing systems. Frontiers in Built Environment 2019; 5: 104. https://doi.org/10.3389/fbuil.2019 .00104 .

[21] Di Cesare A, Ponzo FC, Lamarucciola N, Nigro D. Experimental post-tensioning losses of a post-tensioned timber framed model with dissipative systems. 8th International Conference on Computational Methods in Structural Dynamics and Earthquake Engineering (COMPDYN 2021), 27-30 June 2021, Streamed from Athens, 2: 3982-3991.

[22] Di Cesare A, Ponzo FC, Lamarucciola N, Nigro D. Dynamic Seismic Response of Nonlinear Displacement Dependent Devices versus Testing Required by Codes: Experimental Case Studies. Applied Sciences 2020; 10(24): 8857. https://doi.org/10.3390/app10248857. 